\title{
Fluorine F 18 CP18 Peptide
}

National Cancer Institute

\section{Source}

National Cancer Institute. Fluorine F18 CP18 Peptide. NCI Thesaurus. Code C97134.

A triazole containing pentapeptide labeled with the positron-emitting isotope fluorine $F$ 18 , used as a tracer for positron emitting tomography (PET) imaging. As a caspase-3 specific substrate, fluorine F 18 CP18 peptide is preferentially taken up by and accumulates in tumor cells with high caspase-3 activity. Upon PET imaging, apoptotic cells can be detected and apoptotic activity can be assessed. Caspase- 3 is a cysteine protease that plays a key role in the induction of apoptosis. 